\title{
A Systematic Review and Model Development of the Factors that Affect Knowledge Sharing in Educational Institutions
}

\author{
Samera Ali Abdullah ${ }^{1}$, Rosnafisah Bt Sulaiman ${ }^{2}$ \\ College of Post Graduate Studies, University Tenaga Nasional, Jalan IKRAM-UNITEN, 43000 Kajang, Selangor, Malaysia \\ College of Information Technology, University Tenaga Nasional, Jalan IKRAM-UNITEN, 43000 Kajang, Selangor, Malaysia
}

\begin{abstract}
Knowledge sharing is one of the most important practices of Knowledge Management (KM). Most studies focused on knowledge sharing in business organizations, but not many studies can be found on knowledge sharing in educational institutions. Researchers have not come to an agreement regarding the factors that affect knowledge sharing behavior. The purpose of this study is to review and integrate the literature to identify the factors that affect knowledge sharing behavior in educational institutions. A systematic literature review was conducted. Ten articles matched the inclusion criteria. The findings showed the majority of the articles were empirical and a total of $50 \%$ of the study was conducted in Malaysia. Academic staff was used by $90 \%$ of the study as target respondents. In addition, the findings showed that the factors that affect knowledge sharing are attitude, technology, rewards, culture, top management, and reputation. A propose model was developed and directions for future work are given.
\end{abstract}

Keywords: Knowledge sharing, Academic Staff, Attitude, Systematic Literature Review, Technology

\section{Introduction}

During the last decades, studies and theories in Knowledge Management (KM) have provided empirical evidences that knowledge is the ultimate sources of competitive advantage and superior performance [1], [2], [3], [4], [5]. Knowledge management includes practices such as knowledge creation, acquisition, integration, and sharing of information, insight, wisdom, thought, inductions, and the application of knowledge [6]; [7]. Organizations, who have adopted KM, are truly getting the benefits of better decision making, quicker response, increased profit and improved productivity [8], [9], [10]. Knowledge sharing is one of the fundamental practices of KM. Several studies showed that the benefits of $\mathrm{KM}$ can only be attained once the knowledge is shared among organizational members [11], [12]. Knowledge sharing is defined as behavior, experiences through what knowledge, skills, or expertise, is exchanged among staff [13].

Knowledge sharing is an essential practice that leads to better organizational performance, reduction of operational cost, innovation, and competitiveness [14], [15]. Due to the benefits of knowledge sharing, previous studies have attempted to identify the factors, motives, and antecedents that lead organizational member to share their knowledge [16], [17], [18]. However, the majority of the previous studies has been conducted in business organizations. Few studies have investigated the knowledge sharing behavior in educational institutions such as universities [19], [20], [21]. Further, researchers who have investigated the knowledge sharing in the educational institutions have not come to an agreement regarding the factors that affect academic or nonacademic staff to share their knowledge. Previous studies associated the knowledge sharing behavior with factors such as culture [22], [23], rewards [24], [19], attitude [27], Information Technology (IT) infrastructure [26], [24], [25], and individual characteristic such as self-efficacy and reputation among others [19], [28].

The purpose of this study is to review and integrate the literature to identify the factors that affect the knowledge sharing behavior in the higher educational institutions. This is supported by the lack of the studies in this area and the need to have a deep understanding of these factors so that the higher educational institutions can use the findings of this study to improve the knowledge sharing behavior. The study consists of five sections. First, the study introduces the topic and highlights the issues. Second, it systematically reviews the related literature of knowledge sharing. Third, the study describes the research methodology. Fourth, the study presents the findings. Lastly, the study presents the conclusion and provides the direction for future work.

\section{Literature Review}

\section{A. Knowledge Sharing in Higher Educational Institutions}

In higher educational institutions, the knowledge of academic staff in the same faculty is seldom shared with colleagues in systematic and meaningful way [29]. Fear of knowledge revelation is cited as one of the most important barriers that lead academic staff to not share their knowledge with others [29]; [27]. Therefore, despite the fact that the university is the center for knowledge creation, the knowledge is not being shared and utilized effectively [30], [31]. Knowledge sharing is defined as the fundamental means through which employees can contribute to knowledge application, innovation, and ultimately the competitive advantage of the organization [32]. Based on the definition, universities will not achieve several advantages if the knowledge of the organizational member has not been shared. Researchers highlighted the need for knowledge sharing to produce new ideas and to help each other in solving problems and implementing new policies and 


\section{International Journal of Science and Research (IJSR) \\ ISSN (Online): 2319-7064}

Index Copernicus Value (2013): 6.14 | Impact Factor (2014): 5.611

procedures. Individuals can share their knowledge via many means such as face-to-face, lectures, workshops, online discussion among other [33].

\section{B. Summary of Reviewed Articles}

Empirical evidence showed that knowledge sharing has many benefits for individuals and organizations such as universities. However, many barriers prevent the knowledge from being shared among academic and non-academic staff. As a result, previous studies attempted to understand the factors that affect knowledge sharing behavior among academicians. For example, [28] conducted a case study to identify the factors that affect the motivation of academicians to share their knowledge in academic institutions in Malaysia. The study collected data using semi-structured interview method. The findings indicated that acknowledgement, mentoring, vision and mission, build reputation, knowledgeable, personal belief, and reciprocity are the most important factors that affect the knowledge sharing behavior among academic staff.

Similarly, Tan et al. [19] investigated the knowledge sharing behavior among academicians in Malaysia. They incorporated factors such as commitment, enjoyment in helping others, reputation, organizational reward, and reputation. The data were collected from 373 respondents. The findings indicated that all the factors have a significant relationship with attitude to share knowledge which in turn affects significantly the intention to share knowledge.

Cheng et al. [22] conducted a quantitative study in Malaysia to find the factors that affect the knowledge sharing in an academic institution. Independent variables included culture, structure, and information technology. Data was collected from 60 students at Multimedia University in Malaysia. The findings showed that culture, structure, and information technology havea significant effect on knowledge sharing.

Nistor et al. [26] investigated the role of educational technology and online communities of practice (CoP) on knowledge sharing among faculty members in Germany. They adopted as a theoretical adoption model the Unified Theory of Acceptance and Use of Technology (UTAUT) which has factors such as performance expectancy, effort expectancy, social influence, facilitating condition, and participation in CoP. Data was collected from 72 faculty members in Germany. The findings indicated that educational technology as well as COP have a significant effect on behavioral intention and use behavior to share knowledge.

Ali et al. [21] conducted a literature review study on the factors that affect the knowledge sharing in academia. The inclusion criteria of the study were only for academic staff and the study was more into cultural factors of knowledge sharing among developing countries. The findings showed that individual, national and professional team as well as the language issues, and trust are the factors that can affect the knowledge sharing behavior among academic staff in higher educational institutions.

Fullwood et al. [24] investigated the factors that affect the knowledge sharing behavior among academicians at United
Kingdom (UK) universities. The findings of the study showed that rewards and associations, expected contribution, normative beliefs, leadership, structure, autonomy, affiliation to an institution, affiliation to discipline, and technology are the most significant factors.

In similar approach, Jan et al. [23] found that knowledge sharing behavior of academicians is affected by five factors: nature of knowledge, culture, motivation, attitude, and opportunities to share. Babalhavaeji and Kermani [21] conducted a study in Iranian university and found the factors of knowledge sharing are attitude, intention and intrinsic motivation. Jain et al. [23] explored the factors affecting knowledge sharing activities among academic staff in Business Schools in Malaysia. The finding showed that trust, culture, and structure are the most important factors. Nassuora and Hasan [34] in their survey conducted among 50 academic staff in a Malaysian university showed that, mobile phone technology and attitude were the main motivator factors for knowledge sharing among the academicians.

\section{Research Methodology}

This paper presents a systematic literature review in the area of knowledge sharing. Our search investigation began with identifying the related articles. The search involves two steps. First, it involves the search for related articles of knowledge sharing. Keywords such as knowledge sharing, higher learning institution, factors affect knowledge sharing, and a combination of these words was used to identify the articles that fell under this topic and with the pre-identified keywords. Databases such as Emerald, Google search engine (Google scholar), ScienceDirect, and ProQuest were utilized for this purpose. As a result, a total of 267 articles was identified. The inclusion criteria for the review articles are to be recently published between 2009 until 2015 . KM in its current form was emerged during the late 1990s and knowledge sharing studies increase gradually since that time. However, the knowledge sharing was affected by the emergence of web based technologies and social media, which appeared and widely spread during 2008-2009. Other inclusion criteria are knowledge sharing in higher educational institutions.

The exclusion criteria that were used in this selection process are: year of publication prior to 2009, non-English publication, technical articles, non-knowledge sharing articles, business knowledge sharing articles. Three levels of screening processes were conducted. First, the initial screening was conducted by reading the title of the articles. As a result, a total of 214 articles were excluded because majority of the titles are related to business studies. The second screening process was based on the title, abstract, and pre-identified keywords. As a result, 35 articles were excluded. These articles were technically oriented and were not considered for this systematic literature review. The third screening was to check the date of publication. As a result eight articles were excluded because they were published prior to 2009. Figure Ishows the systematic literature review process. 


\section{International Journal of Science and Research (IJSR) \\ ISSN (Online): 2319-7064}

Index Copernicus Value (2013): 6.14 | Impact Factor (2014): 5.611

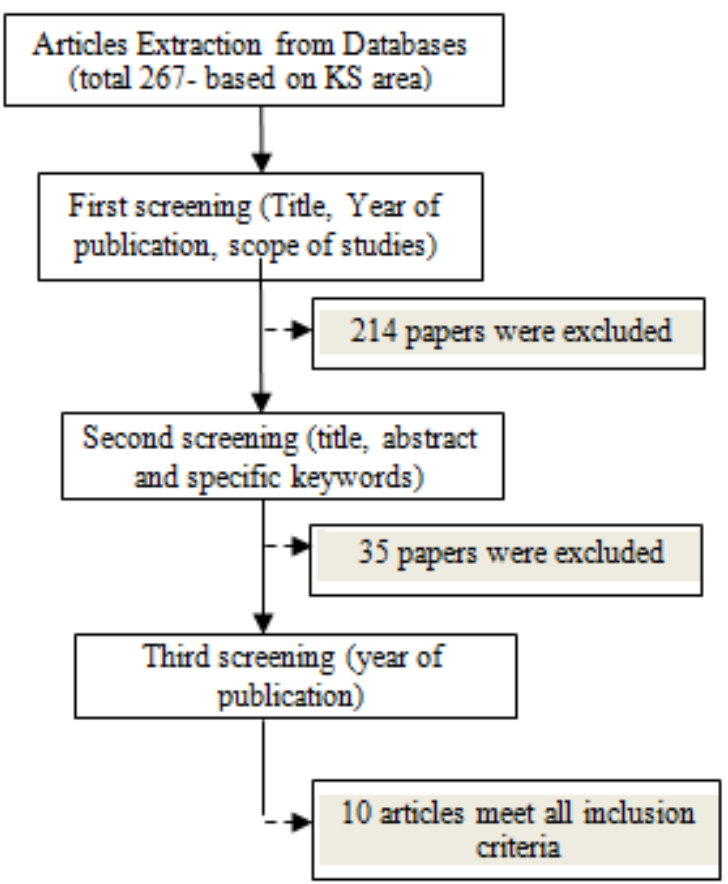

Figure 1: Systematic Literature Review Processes

In depth reading and review of the ten articles was performed and findings from these articles were extracted. A frequency analysis was conducted on the extracted findings to determine the most frequent factors that have been used in the previous studies.

\section{Results and Discussion}

The analysis of the study showed that $90 \%$ of the reviewed articles were conducted using academic staff as respondents. A total of $10 \%$ has used the students as target respondents. In addition, the majority of the studies (about 90\%) were empirical while others were based literature review studies. Mainly the studies were conducted in Malaysia (50\%), Germany $(10 \%)$, UK (10\%), Iran (10\%), and globally about $20 \%$

\section{a) Factor Affect Knowledge Sharing}

A frequency analysis of the factors that have been used in the previous studies was conducted. Table 3 shows factors that have been extracted from the previous articles and their frequency. It is important to mention that a combination of factors that have similar meaning and different wording has been conducted. For example, factors such as IT system, IT infrastructure, and technology were combined in one factor named technology. In addition, factors such as leadership and top management were combined in one factor named top management.

Table 1: Extraction of Factors From 10 Articles

\begin{tabular}{|c|c|c|c|c|c|c|c|c|c|c|c|}
\hline Factor & M1 & M2 & M3 & M4 & M5 & M6 & M7 & M8 & M9 & M10 & $\mathrm{F}$ \\
\hline Culture & $\mathrm{X}$ & & & & & $\mathrm{X}$ & & $\mathrm{X}$ & & & 3 \\
\hline Personal expectation & $\mathrm{X}$ & & & & & & & & & & 1 \\
\hline Technology & $\mathrm{X}$ & $\mathrm{X}$ & & $\mathrm{X}$ & $X$ & & & $\mathrm{X}$ & & & 5 \\
\hline Reward & $\mathrm{X}$ & $\mathrm{X}$ & $\mathrm{X}$ & & & & & & & & 3 \\
\hline Top Management & $\mathrm{X}$ & $\mathrm{X}$ & & & & & & & $\mathrm{X}$ & & 3 \\
\hline Structure & & $\mathrm{X}$ & & & & & & & & & 1 \\
\hline Normative belief & & $\mathrm{X}$ & & & & & & & & & 1 \\
\hline Autonomy & & $\mathrm{X}$ & & & & & & & & & 1 \\
\hline Affiliation to institution & & $\mathrm{X}$ & & & & & & & & & 1 \\
\hline Affiliation to discipline & & $\mathrm{X}$ & & & & & & & & & 1 \\
\hline Enjoyment & & & $\mathrm{X}$ & & & & & & & & 1 \\
\hline Reputation & & & $\mathrm{X}$ & & $X$ & & & & $X$ & & 3 \\
\hline Attitude & $X$ & & $\mathrm{X}$ & $\mathrm{X}$ & $\mathrm{X}$ & $X$ & $X$ & & & & 6 \\
\hline Software users & & & & $\mathrm{X}$ & & & & & & & 1 \\
\hline Nature of knowledge & & & & & & $\mathrm{X}$ & & & & & 1 \\
\hline Motivation & & & & & & $\mathrm{X}$ & $\mathrm{X}$ & & & & 2 \\
\hline Trust & & & & & & & & $\mathrm{X}$ & & & 1 \\
\hline Layout & & & & & & & & $\mathrm{X}$ & & & 1 \\
\hline Formal and informal activities & & & & & & & & $\mathrm{X}$ & & & 1 \\
\hline Fear of & & & & & & & & $\mathrm{X}$ & & & 1 \\
\hline Communication & & & & & & & & $\mathrm{X}$ & & & 1 \\
\hline Acknowledgement & & & & & & & & & $\mathrm{X}$ & & 1 \\
\hline Mentoring & & & & & & & & & $\mathrm{X}$ & & 1 \\
\hline Vision and mission & & & & & & & & & $\mathrm{X}$ & & 1 \\
\hline Knowledgeable & & & & & & & & & $\mathrm{X}$ & & 1 \\
\hline Personal belief & & & & & & & & & $\mathrm{X}$ & & 1 \\
\hline Reciprocity & & & & & & & & & $\mathrm{X}$ & & 1 \\
\hline Social influence & & & & & & & & & & $\mathrm{X}$ & 1 \\
\hline Facilitating condition & & & & & & & & & & $\mathrm{X}$ & 1 \\
\hline Performance expectancy & & & & & & & & & & $\mathrm{X}$ & 1 \\
\hline Effort expectancy & & & & & & & & & & $\mathrm{X}$ & 1 \\
\hline Participation in CoPs & & & & & & & & & & $\mathrm{X}$ & 1 \\
\hline
\end{tabular}

It can be seen that the most frequent factor is the attitude with frequency of six times. The frequency and the incorporation of this variable indicates that the attitude toward knowledge sharing is an important factor. It can be seen also that the frequency of other factors such as technology is high. This could be related to the fact that knowledge sharing in these 


\section{International Journal of Science and Research (IJSR) \\ ISSN (Online): 2319-7064}

Index Copernicus Value (2013): 6.14 | Impact Factor (2014): 5.611

days occurs via online means such as a social media website, or Smartphone's applications. Other factors carry the same frequency of three times and they are rewarded, culture, reputation, and top management. Table II shows the frequency of the factors and the operational definitions.

Table 2: Frequent factors and their definitions

\begin{tabular}{|c|c|c|}
\hline Factor & Frequency & Operational definitions \\
\hline Attitude & 6 & $\begin{array}{c}\text { The willingness to share knowledge with } \\
\text { employees }\end{array}$ \\
\hline Technology & 5 & $\begin{array}{c}\text { Systems that can store, retrieve, } \\
\text { manipulate, transmit or receive } \\
\text { information electronically in a digital } \\
\text { form. }\end{array}$ \\
\hline Rewards & 3 & $\begin{array}{l}\text { The monetary and non-monetary } \\
\text { advantages that employees gain from the } \\
\text { organization. }\end{array}$ \\
\hline Culture & 3 & $\begin{array}{c}\text { Consistent, observable patterns of } \\
\text { behaviour in organizations. Two major } \\
\text { assumptions which are beliefs and values }\end{array}$ \\
\hline Reputation & 3 & $\begin{array}{l}\text { The positive word of mouth that } \\
\text { employees wishes to be attributed with if } \\
\text { they share their knowledge }\end{array}$ \\
\hline $\begin{array}{c}\text { Top } \\
\text { Management }\end{array}$ & 3 & $\begin{array}{l}\text { The influence of other employees in the } \\
\text { organization, family, and society on } \\
\text { employee to share the knowledge }\end{array}$ \\
\hline
\end{tabular}

\section{Discussion}

The findings of this study indicated that the most frequent and used factors are attitude, followed by technology, rewards, culture, reputation, and top management. Most theories proposed that attitude toward the action is essential for the behavior and the actual action. Technology Acceptance Model (TAM) by Davis (1989) argued that attitude is the motive for behavior and actual action. The reviewed studies focused on attitude because it is essential for the knowledge sharing behavior[27].

Technology can foster the development of knowledge sharing culture and helps in the knowledge transfer between individuals and departments. It is a means that can be used to store, retrieve and access structured knowledge. The knowledge sharing requires the use of IT-based applications and software. Social media for example, is a perfect environment for knowledge sharing. It is enabled by the Internet. The existence of these applications and services facilitates the knowledge sharing [26], [24]. Rewards whether financial or non-financial have an effect on the knowledge sharing behavior. Researchers suggested that employees will repeat the behaviors that are rewarded by the management of the organizations.

The culture of the organizations who promotes trust and openness is an encouraging culture for the employee to share their knowledge with other organizational member [6]. In addition, the reputation of the employees is important because employees like to be associated with positive reputation of being knowledgeable and a source of organizational knowledge. This feeling gives them a motive to share their knowledge among organizational members.Overall, these practices would not be possible without effective management that support the creation of knowledge culture and reward those who are participating in knowledge sharing activities.

The findings showed also that most of the studies have been conducted in Malaysia and the majority was conducted on academic staff. Our findings are in agreement with the findings of [21] who found knowledge sharing studies in developing countries were mainly conducted in Malaysia. They found also that the majority has used academic staff as target respondents.

It can be seen that the most frequent factors can be categorized as individual factors (reputation, attitude), organizational factors (reward, top management, culture) and technology related factors (technology). A propose model could be developed from these factors to help organizations to foster the knowledge sharing behaviour. Since knowledge sharing is associated with several organizational outcomes such as competitiveness, innovation, and organizational performance, the propose model could be developed from the antecedents and outcomes of knowledge sharing. Figure II presents the proposed knowledge sharing model for educational institutions.

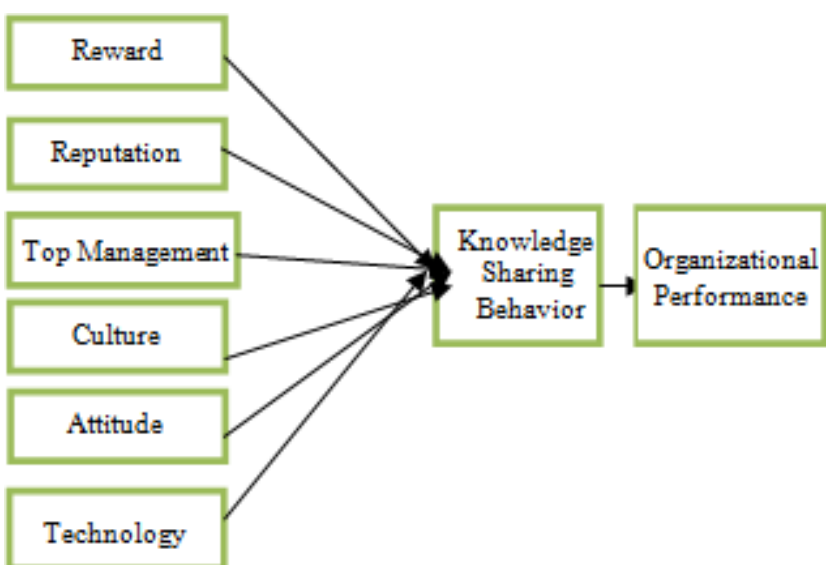

Figure 2: Proposed Conceptual Model

Thus, the hypotheses that reflect the model are

H1: Rewards have significant effect on knowledge sharing behaviour

H2: Reputation has a significant effect on knowledge sharing behaviour

H3: Top management has a significant effect on knowledge sharing behaviour

H4: Culture has a significant effect on knowledge sharing behaviour

H5: Attitude toward knowledge sharing has a significant effect on knowledge sharing behaviour.

H6: Technology has a significant effect on knowledge sharing behaviour.

H7: Knowledge sharing behaviour has a significant effect on organizational performance.

\section{Limitation and Recommendation for Future Work}

The findings of this study were based on the findings of ten articles that have investigated knowledge sharing in educational institutions. Despite that we have conducted a systematic literature review and come with these articles. 


\section{International Journal of Science and Research (IJSR) \\ ISSN (Online): 2319-7064}

Index Copernicus Value (2013): 6.14 | Impact Factor (2014): 5.611

Future studies could expand the inclusion criteria to include more articles so that the result could be more generalizable. Our findings revealed that the majority of the studies was conducted on knowledge sharing among academic staff. It is recommended for future work to use as non-academic staff target respondents. Future work could also employ diversified respondent such as academic, non-academic staff, and student and compare the knowledge sharing factors between these three types of respondents.

The findings showed that $50 \%$ of the studies were conducted in Malaysia. However, none of the studies have used nonacademic staff as target respondents. Thus, as a way forward, we will conduct an empirical study using to test the propose model by employing non-academic staff as target respondents. This is to observe the knowledge sharing pattern among non- academic staff and how the findings could be used to improve job performance and business operations.

\section{Conclusion}

The purpose of this study was to identify the factor that affects knowledge sharing behaviour at educational institutions. A systematic literature review was conducted on ten articles that match the inclusion criteria of this study. The findings showed that attitude is the most important factor that has been used by researchers. This is followed by technology, rewards, culture, top management, reputation. The findings also showed that the majority of the reviewed studies were empirical and they have been conducted in Malaysia and other countries using academic staff as target respondents. Based on the review, we proposed a model that can be used by organization to foster the development of knowledge sharing. The proposed model consisted ofthe antecedents and the outcome of knowledge sharing. Accordingly, the related hypotheses were stated. In addition, we highlighted the main limitations of our findings and suggested the direction for future work.

\section{References}

[1] Spender, J. C., \& Grant, R. M. (1996). Knowledge and the firm: overview.Strategic management journal, 17(S2), 5-9

[2] Bustamam, U. S. A., Shukor, S. A., Aziz, M. R. A., \& Mohamed, Z. A. (2012). Business Process Reengineering (BPR): Speeding Up Business Licensing Process In A State Government Agency. International Public Sector Conference (IPSC), 25-26 September 2012 at Sutera Harbour Resort, Kota Kinabalu, Sabah, Malaysia

[3] Supar, N., Ibrahim, A. A., Mohamed, Z. A., Yahya, M., \& Abdul, M. (2005). Factors affecting knowledge sharing and its effects on performance: a study of three selected higher academic institutions. In International Conference on Knowledge Management (ICKM).

[4] Sambasivan, M., Loke, S. P., \& Abidin-Mohamed, Z. (2009). Impact of knowledge management in supply chain management: a study in Malaysian manufacturing companies. Knowledge and Process Management, 16(3), 111-123.
[5] Grant, R. M. (1996). Toward a Knowledge-Based Theory of the firm. Strategic management journal, 17(S2), 109-122.

[6] Gold, A. H., Malhotra, A., \& Segars, A. H. (2001). Knowledge management: an organizational capabilities perspective. $J$. of Management Information Systems, 18(1), 185-214.

[7] Gooijer, F.D. (2000). "Designing A Knowledge Management Performance Framework." Journal of Knowledge Management. 4(4). 303-310.

[8] Nieves, J., \& Haller, S. (2014). Building dynamic capabilities through knowledge resources. Tourism Management, 40, 224-232.

[9] Villar, C., Alegre, J., \&Pla-Barber, J. (2014). Exploring the role of knowledge management practices on exports: A dynamic capabilities view. International Business Review, 23(1), 38-44.

[10] Parlby, D. (1998). Knowledge management research report 1998. KPMG Management Consulting, London.

[11]Zhang, X., De Pablos, P. O., \& Xu, Q. (2014). Culture effects on the knowledge sharing in multi-national virtual classes: A mixed method. Computers in Human Behavior, 31, 491-498.

[12] Chen, Y. H., Lin, T. P., \& Yen, D. C. (2014). How to facilitate inter-organizational knowledge sharing: The impact of trust. Information \& Management, 51(5), 568578.

[13] Šajeva, S. (2014). Encouraging Knowledge Sharing among Employees: How Reward Matters. ProcediaSocial and Behavioral Sciences, 156, 130-134.

[14] Lu, H. P., \& Hsiao, K. L. (2007). Understanding intention to continuously share information on weblogs. Internet Research, 17(4), 345-361

[15] Cockrell, R. C., \& Stone, D. N. (2010). Industry culture influences pseudo-knowledge sharing: a multiple mediation analysis. Journal of Knowledge Management, 14(6), 841-857.

[16] Cabrera, E. F., \& Cabrera, A. (2005). Fostering knowledge sharing through people management practices. The International Journal of Human Resource Management, 16(5), 720-735.

[17] Pi, S. M., Chou, C. H., \& Liao, H. L. (2013). A study of Facebook groups members' knowledge sharing. Computers in Human Behavior, 29(5), 1971-1979

[18] Connelly, C. E., \& Kelloway, E. K. (2003). Predictors of employees' perceptions of knowledge sharing cultures. Leadership \& Organization Development Journal,24(5), 294-301.

[19] Tan, C. N. L., \& Ramayah, T. (2014). The Role of Motivators in Improving Knowledge-Sharing among Academics. Information Research: An International Electronic Journal, 19(1), n1.

[20] Jolaee, A., Md Nor, K., Khani, N., \& Md Yusoff, R. (2014). Factors affecting knowledge sharing intention among academic staff. International Journal of Educational Management, 28(4), 413-431.

[21] Ali, O. F., Gohneim, A., \& Al Roubaie, A (2014). Knowledge Sharing Culture in Higher Education Institutions: Critical Literature Review. European, Mediterranean \& Middle Eastern Conference on Information Systems 2014 (EMCIS2014) October 27th - 28th 2014, Doha, Qatar. 


\section{International Journal of Science and Research (IJSR) \\ ISSN (Online): 2319-7064}

Index Copernicus Value (2013): 6.14 | Impact Factor (2014): 5.611

[22] Cheng, M. Y., Ho, J. S. Y., \& Lau, P. M. (2009). Knowledge sharing in academic institutions: A study of multimedia university malaysia. Electronic journal of knowledge management, 7(3), 313-324.

[23] Jain, K. K., Sandhu, M. S., \& Goh, S. K. (2015). Organizational climate, trust and knowledge sharing: insights from Malaysia. Journal of Asia Business Studies, 9(1), 54-77.

[24] Fullwood, R., Rowley, J., \& Delbridge, R. (2013). Knowledge sharing amongst academics in UK universities. Journal of knowledge management, 17(1), 123-136.

[25] Alaarj, S. Abidin-Mohamed, Z. \&Bustamam, U., S., A., (2015). The Effect of Knowledge Management Capabilities on the Performance of Malaysian LargeScale Organizations: An Empirical Study. AGBA's 12th World Congress.

[26][26] Nistor, N., Baltes, B., \& Schustek, M. (2012). Knowledge sharing and educational technology acceptance in online academic communities of practice. Campus-Wide Information Systems, 29(2), 108-116.

[27] Babalhavaeji, F., \& Kermani, Z. J. (2011). Knowledge sharing behavior influences: a case of Library and Information Science faculties in Iran. Malaysian journal of library \& information science, 16(1), 1-14.

[28] Abdullah, S., \& Haron, H. (2013). Knowledge sharing system model for higher learning institutions: Case Study. In advanced computer science applications and technologies (ACSAT), 2013 International conference on (pp. 97-102). IEEE.

[29] Khalil, O. E., \& Shea, T. (2012). Knowledge sharing barriers and effectiveness at a higher education institution. International Journal of Knowledge Management (IJKM), 8(2), 43-64.

[30] Tian, J., Nakamori, Y., \& Wierzbicki, A. P. (2009). Knowledge management and knowledge creation in academia: a study based on surveys in a Japanese research university. Journal of Knowledge Management, 13(2), 76-92.

[31] Luo, H. (2009). Determinants of knowledge sharing in university academic team. In Knowledge Acquisition and Modeling, 2009. KAM'09. Second International Symposium on (Vol. 1, pp. 260-263). IEEE.

[32] Jackson, S. E., Chuang, C. H., Harden, E. E., \& Jiang, Y. (2006). Toward developing human resource management systems for knowledge-intensive teamwork. Research in personnel and human resources management, 25, 27-70

[33] Cummings, J. N. (2004). Work groups, structural diversity, and knowledge sharing in a global organization. Management science, 50(3), 352-364.

[34] Nassuora, A. B., \& Hasan, S. (2010). Knowledge Sharing among Academics in Instituitions of Higher Learning. In 5th Knowledge Management International Conference, Terengganu, Malaysia, May. 